\title{
Inscrição de alteridade, artefatização do olhar: a fotografia de sujeitos vulneráveis em Lee Jeffries
}

\author{
Angie Biondi' \\ https://orcid.org/0000-0002-0486-1081 \\ Rafael Tassi Teixeira" \\ https://orcid.org/0000-0001-7137-0904 \\ I - Universidade Tuiuti do Paraná \\ Curitiba (PR), Brasil \\ II - Universidade Tuiuti do Paraná; \\ Universidade Estadual do Paraná \\ Curitiba (PR), Brasil
}

Resumo: O trabalho retoma o conjunto fotográfico Lost Angels (2014), de Lee Jeffries, que retrata pessoas em situação de rua nos grandes centros urbanos, para pensar como os efeitos da estruturação da imagem fotográfica constituem uma relação de alteridade contingencializada. Através dos retratos de sujeitos vulneráveis, Jeffries assina modos de convocação do olhar articulados entre a codificação desejada e a regularização da dimensão estética. Nessa dualidade particular, as imagens são examinadas a partir das repercussões possíveis em regimes de figuração que acionam certo deleite visual conforme modos de convocação da presença dos sujeitos. Discutimos como a fotografia documental ainda poderia oferecer operadores visuais nas tópicas do retrato humano e qual sua designação específica nas exposições destes sujeitos em uma perspectiva plástica e conversacional da imagem.

Palavras-chave: fotografia documental; invisibilidade; vulnerabilidade.

Abstract: Inscription of alterity, artifactization of the gaze: the photography of vulnerable people in Lee Jefries - This paper takes up the photographic work Lost Angels (2014), by Lee Jefries, which portraits people living on the streets in large urban centers, to think about how the effects of the structure in photographic image constitute a contingent relationship of alterity. Through these portraits of vulnerable people, Jeffries signs ways to summon the look articulated between the desired codification and the regularization of the aesthetic dimension. In this duality, the images are examined based on the possible repercussions of the modes of figuration that trigger a certain visual delight according to the ways in which the presence of people 
is called upon. We reflect on how documentary photography could offer visual operators in the topics of human portrait and what is its specific designation in these subjects' exposures in a plastic and conversational perspective of the image.

Keywords: documentary photography; invisibility; vulnerability.

Até onde vai nosso direito de olhar para os outros, pensando definir suas identidades através de nossas fotografias? (Etienne Samain, 2014)

\section{Introdução}

Como um território de locução cultural, a fotografia é permeada de densidade intersubjetiva, e se torna importante na assignação pragmática da relação entre corpos, subjetividades, experiências e pertencimentos. Para além do entendimento como fato social e psíquico, a imagem fotográfica ajuda a constituir as representações materiais que se tem do mundo na acepção perceptiva e negociada da esfera do domínio das imagens. Essa densidade conversacional está longe de animar apenas um gesto comum de artefatização cultural, que pode ser entendido, também, na tensão entre a visualidade das fotos e sua inscrição nos diferentes usos e estatutos da imagem.

$\mathrm{O}$ artigo busca compreender como a figuração e o ato de constituir uma imagem desafiam o próprio processo de engajamento crítico nos regimes de representação documental que parecem marcar os retratos de sujeitos em posições de vulnerabilidade. É o que se observa, por exemplo, na série intitulada Lost Angels, do fotógrafo Lee Jeffries, quando enfatiza pessoas em situação de rua, usadas como tópicas visuais de seu trabalho. O interesse é problematizar a fotografia documental como um gênero que se engendra na impossibilidade de promover a circulação a partir da convocação unívoca do olhar, observada, especificamente, no trabalho de Jeffries sobre sujeitos vulneráveis e em situação de rua. Interessa-nos discutir como a fotografia do artista compõe uma gramática da experiência visual que torna a codificação desejada, em geral, um veredicto sobre a dimensão plástica da imagem.

Este texto propõe um exercício de análise baseado nas seguintes questões-chave: a) em que medida, ao observar as pessoas em situação de rua, vulneráveis e marginalizadas, o acionamento da iconografia específica da fotografia acaba comprometendo o próprio modus operandi da figurativização em sujeitos em que a condição de invisibilidade é regularizada e tipificada; b) até que ponto as imagens dos sujeitos, em Jeffries, podem ser potencialmente políticas, e quais seriam as repercussões possíveis das fotografias no trabalho Lost Angels ao encamparem o limite da identidade social; c) como os sujeitos, percebidos a partir da vulnerabilidade exposta nas imagens, estariam regulados em 
uma experiência estética baseada na dimensão cênica. Diante da legibilidade, tais sujeitos estariam mais arroupados pela mensagem conversacional das fotografias?

\section{Expor os vulneráveis em documentos visuais}

O pesquisador Michel Mollat (1998), em seus trabalhos sobre coleções fotográficas que compunham a historiografia da pobreza na Europa medieval, classificou como souspauvres, uma curiosa categoria de sujeitos, que eram não apenas despossuídos de bens materiais, mas desprovidos de qualquer meio de se revelar ou se manifestar, publicamente, por si próprios. Em sua definição, sous-pauvres constituíam os grupos mais empobrecidos, que viviam às margens dos centros urbanos e realizavam algum tipo de serviço considerado indigno às outras camadas sociais.

Mesmo trabalhadores, eles recebiam baixíssima remuneração tornando-se incapazes de garantir um sustento familiar mínimo. Pertenciam a esta categoria social: catadores, curtidores de couro ou de lã, limpadores. Apesar de desempenharem algum serviço necessário, eles viviam em situação de fome e penúria constante, o que reforçava a necessidade de ajuda de governos e outras instituições - geralmente, a Igreja. Tratava-se de uma camada da população que vivia sob uma constante condição de precariedade que lhe impossibilitava, entre outras coisas, o exercício da autorrevelação pública, pois deveriam habitar e transitar apenas pelos bolsões marginais dos crescentes centros urbanos. Mollat (1998) indica que a privação e o anonimato eram duas características essenciais que mantinham, conjugados, a invisibilidade e o silêncio destas pessoas. Sem possibilidade de falarem por si ou de mostrarem sua existência precária, os sous-pauvres compunham um grupo de sujeitos marginalizados, excluídos do direito à cidade, à vida pública e, por conseguinte, à própria voz e à própria imagem.

Retomar este aspecto histórico acerca da representação dos sujeitos empobrecidos e marginalizados ajuda a estabelecer comparativos importantes no esforço da observação destas classificações sobre sujeitos extremamente empobrecidos na atualidade, e compreender que tipo de visibilidade lhes é atribuída através dos materiais culturais que circulam no cotidiano. Tais sujeitos, ainda hoje, não constituem um grupo social que tem assegurado o pleno direito à palavra e à imagem própria. Sua condição econômica e social parece estabelecer, ainda, uma interface estético-política nos mesmos moldes daqueles analisados por Mollat.

É preciso lembrar que foi no período moderno que a fotografia se aliou a outros registros visuais documentais no intuito de conhecer quem eram, e como viviam, os precários e anônimos da sociedade. A fotografia documental entraria em pleno vapor rumo ao seu projeto de inventariar os povos nos séculos subsequentes. Como indica Margarita Ledo (1998), o uso do recurso fotográfico fez com que nos aproximássemos do "sonho da verdade empírica, a confiança na câmera passa a fazer parte das mentalidades e 
a ser um artefato aplicável às instituições garantidoras da ordem administrativa ou policial" (LEDO, 1998, p.68). Neste sentido, o registro e a captura fotográfica passaram a colocar em evidência o entrelaçamento do documento fotográfico e da escritura documental que, desde cedo, modularam a (in)visibilidade dos sujeitos.

Neste processo, é importante problematizar tanto o gesto quanto seu produto, pois a proliferação das formas de captação do mundo em imagens revela sua base paradoxal; a sobre-exposição leva à subexposição. Ou, nos termos de uma formulação crítica bem própria ao campo da discussão estético-política das imagens hoje: a visibilidade é sempre a revelação de maneiras de fazer ver, sentir e de modos de pensar o mundo incluindo a produção de sua invisibilidade (RANCIÈRE, 2011, p.13).

Em breve paralelo, a função documental da imagem, nos diversos contextos contemporâneos, não enfraquece esta disposição conceitual indicada por Rancière. Certo valor de culto atribuído à imagem documental está hoje evidentemente transformado diante da intensidade do relativismo entre suas formas de produção e legitimação.

A imagem documental, quando no contexto fotográfico, participaria desta mesma relativização. Conforme assinalado por Sontag (2004, p.181), não é a realidade em si mesma o que as fotos tornam imediatamente acessíveis, mas sim as próprias imagens. Desmobilizada a crença de que uma imagem fotográfica revelaria tão somente seu referente, pois estaria atrelada ao valor de verdade inerente ao análogon, a fotografia documental tem sido cada vez mais questionada por seu teor político através de autores que têm procurado investigar as intrincadas relações entre estética e política dispostas em uma sociedade atual constituída, em grande parte, por imagens - e de todo tipo. Daí notarmos o quanto as considerações de um pensador como Jacques Rancière $(2005 ; 2010$; 2011) comparecem em diversas análises que lidam com a imagem como importante objeto de investigação.

A crítica que Rancière endereça ao regime representativo das imagens, que compõe nossa sociedade mesmo em contexto artístico, demonstra o alto grau de expectativa e crença ainda depositado na imagem, seja por aspectos ontológicos ou por conta dos contextos discursivos nos quais participa. Conforme Rancière (2011, p.13), é preciso compreender que uma imagem nunca é uma realidade simples e própria, mas operações entre o dizível e o visível, portanto, uma prática sobre modos de discursividade.

Uma política das imagens não pode ser pensada exclusivamente nos termos de um conteúdo representativo, nem se concretizar como uma instrução para olhar o mundo pensando transformá-lo através da imediata tomada de consciência sobre opressões e sofrimentos que são oferecidos pelas imagens. À representação obsedante do teor factual e do valor de verdade integral, Rancière (2011) contrapõe o gesto da "anti-representação ou o regime estético das artes" (2011, p.158), que não significa, necessariamente, a não figuratividade. Justamente porque não reside no conteúdo da imagem - em seu tema -, o regime estético se definiria como presença. Neste regime estético, portanto, as imagens 
não fazem ver a realidade diretamente ou como se apresentaria nua e crua, mas impõem modos de presença; seria este o movimento que tornaria um modo da apresentação sensível e capaz de descontruir modelos de enquadramentos discursivos ilustrados pelas imagens dos sujeitos, tradicionalmente ${ }^{1}$.

No intuito de ampliar estas questões teoricamente elaboradas e compreender em que medida a imagem documental ainda poderia propor modos de presença que desarticulariam modelos e esquemas discursivos, trazemos para o centro da discussão alguns exemplares recentes da fotografia documental de sujeitos que vivem em situação de rua. Destacamos que observar pessoas nas diversas condições precárias atuais significa, possivelmente, resgatar a constatação de uma persistência da mesma conjugação de (in)visibilidade social evidenciada pela iconografia histórica apontada por Mollat.

É importante ressaltar que, para atentar a este entrecruzamento (condição socioeconômica precária e invisibilidade social), nos apoiamos em uma das críticas tecidas tanto por Estelle Ferrarese (2011a; 2011b), quanto por Judith Butler (2004; 2011; 2015). Tal crítica tem demonstrado como uma discussão mais atualizada da vulnerabilidade precisa desmobilizar uma perspectiva ética e ontológica geral para se centrar em uma discussão política material e concreta, uma vez que a condição de vulnerável comparece quando se constata - visivelmente - situações de abuso, de injúria social, ou seja, quando demarcada e reconhecida em um campo público, vista no entrelaçamento do poder e da violência.

Apenas deste modo, segundo as autoras, seria possível analisar os cenários em que a vulnerabilidade é distribuída de forma desigual entre os sujeitos. Não se trata de entender e classificar um sujeito vulnerável apenas localizando, através dele, uma vitimização ou passividade, ou ainda, uma explicação da condição humana básica e universal de ser vivo submetido às contingências e catástrofes; mas ao contrário, busca-se entendê-lo em uma situação na qual a capacidade de agência e autorrepresentação Ihe é sistematicamente e historicamente - negada, restrita ou regulada por enquadramentos políticos desiguais, inclusive aqueles elaborados no âmbito das imagens.

Deste modo, notamos que aqueles que não possuem as condições materiais mínimas são os mesmos que têm seus direitos de identidade e auto-imagem alijados do espaço público digno dos olhares. Tornados figuras da vulnerabilidade, compareceriam apenas enquanto imagem ilustrativa do um qualquer; sem rosto e sem nome.

\section{Os anjos perdidos de Lee Jeffries}

Ao perambular pelas ruas de grandes cidades ao redor do mundo, o fotógrafo britânico Lee Jeffries produziu uma longa série de imagens retratando moradores de rua. Segundo informações em seu website ${ }^{2}$, o trabalho consiste em um modo de produção muito próximo

1 Esta acepção é bastante significativa, por exemplo, no trabalho de Thierry De Duve (2009), em que as características frontalmente subjetivantes dos regimes fotográficos impõem uma contextualização da imagem diante da necessidade de sua interligação com a presença, permanente e resoluta.

2 Disponível em: <https://lee-jeffries.co.uk/>. Acesso em: 8 abril 2019 mai. 2020. 
ao documental e etnográfico - já que dedica algum tempo ao convívio com os grupos, dialoga e ensaia proximidade e interação com as pessoas fotografadas -, embora críticos e jornalistas o classifiquem, frequentemente, apenas como um street photographer ${ }^{3}$.

Uma de suas produções mais conhecidas é composta por um conjunto que retrata diversas pessoas em situação de rua nos grandes centros urbanos de diferentes países. O livro, lançado em 2014, intitula-se Lost Angels. Em uma entrevista concedida à revista Time, em 2012, Jeffries, ainda no início de sua produção, explica o porquê de nomeá-los assim, e ressalta que seu objetivo era fazer com que compreendêssemos que moradores de rua são pessoas, uma vez que muitos passam por eles como se fossem invisíveis (BICKER, 2012).

O objetivo deste texto não é discutir as intenções do fotógrafo, e menos ainda pôr as imagens à prova quanto às relações entre intenções e efeitos produzidos; mas tentar compreender se/como tais imagens mobilizam o reconhecimento dos sujeitos vulneráveis que retratam, e se/como elas promovem a construção de uma imagem social pública destes sujeitos dissociada das habituais molduras discursivas. Deste modo, as fotografias de Lee Jeffries nos levam a refletir acerca dos aspectos estético-políticos que estariam envolvidos nas imagens documentais recentes de sujeitos em situação de rua, categoria de vulneráveis e marginalizados, quase análoga ao sous-pauvre, uma vez que ainda encarnam, simultaneamente, a despossessão de bens materiais e a destituição do direito à própria imagem.

Em primeiro lugar, propomos o exame de sua potência convocadora do olhar como um possível modo de presença. O retrato, como forma de recursividade elementar da imagem fotográfica, esboça uma espécie de ensaio de comunicação interpessoal na medida em que introduz um vis-à-vis como elemento que gera a opacidade dos limites entre o sujeito que olha e o sujeito que é olhado. Nos retratos trazidos aqui, as noções de objetividade são enfraquecidas para dar lugar às evocações e afecções que parecem se estabelecer com mais força, uma vez que se recorre a um enquadramento que enfatiza a proximidade com a face de cada uma das pessoas. A proposta de aproximação direta com cada um destes sujeitos não visa à mera transmissão de informações sobre sua condição física, de idade, gênero ou classe social, mas realçar as condições precárias que concorrem para o envelhecimento precoce, a aparente solidão, tristeza ou apatia daqueles que fitam a câmera, e do espectador, por conseguinte, ao devolver-lhe o olhar.

Os retratos de Jeffries, de fato, não trazem a história de cada pessoa, nem recontam suas vidas, também não revelam seus nomes nem relatos pessoais, contudo buscam compor, visualmente, uma relação próxima, pessoal, que visa se estabelecer no entreolhar disposto para cada imagem. De modo que cada retratado cumpre uma função vocativa relevante, pois sequer consideramos tais sujeitos que nos fitam como simples personagens

3 Street photography é uma classificação fotográfica. Alguns autores consideram um subgênero da fotografia documental. De todo modo, trata-se de um registro espontâneo e imediato de pessoas como um retrato de momento. O efeito de flagrante e a imediaticidade são aspectos que conferem tanto a validade quanto a veracidade deste tipo de fotografia. 
ou modelos, mas os consideramos figuras dotadas de certa densidade biográfica que, mesmo sem dados, nos informa uma condição vulnerável com a qual nos relacionamos em um nível sensível relativamente mais intenso. Neste sentido, o olhar direto e a proximidade dos sujeitos retratados conferem o valor de uma interlocução pautada em uma espécie de pacto fiduciário por serem inscritas como imagens documentais. Deste modo, a proximidade elaborada nos retratos de Jeffries poderia ser compreendida como uma tentativa de experimentação intersubjetiva colocada através da imagem do sujeito, e não pela remissão aos fatos reais de suas histórias pessoais.
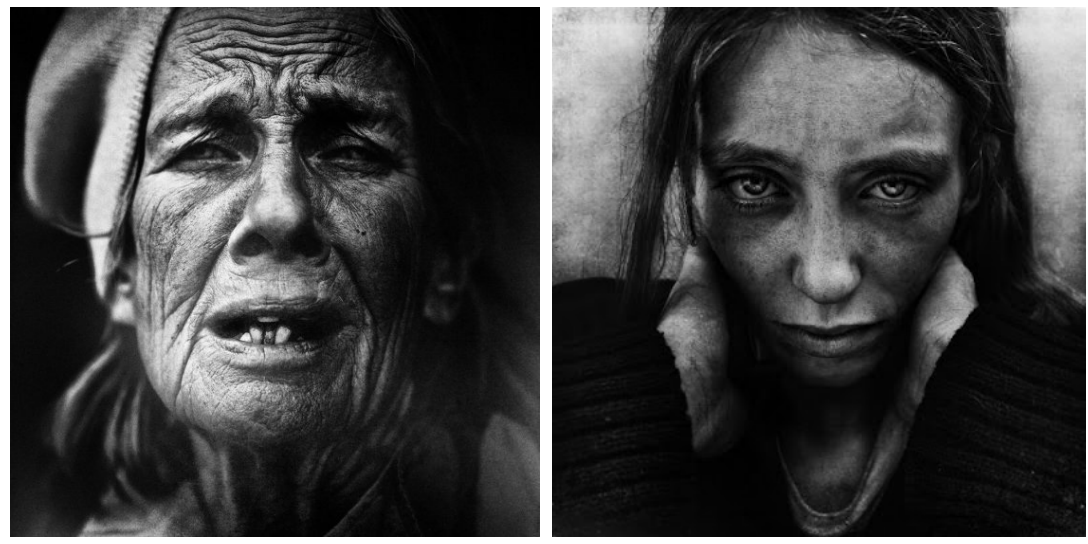

Fig. 1. Fonte: Lee Jeffries. Las Vegas, outubro de 2008. Fig. 2. Fonte: Lee Jeffries. Londres, julho de 2011.

Na figura 1, uma mulher fixa o olhar direto à câmera. Ela tem os lábios entreabertos como se falasse algo, a cabeça levemente inclinada para cima, dentes desalinhados e escurecidos, o rosto enrugado e marcado por sulcos e veios acumulados em uma expressão geral contraída. $\mathrm{Na}$ figura 2, uma mulher jovem também fixa o olhar. Ela tem a cabeça levemente reclinada para baixo e sustentada pelas duas mãos ao redor do pescoço, e fita, frontalmente, com seus grandes olhos esboçando uma expressão sugestiva de certa consternação.
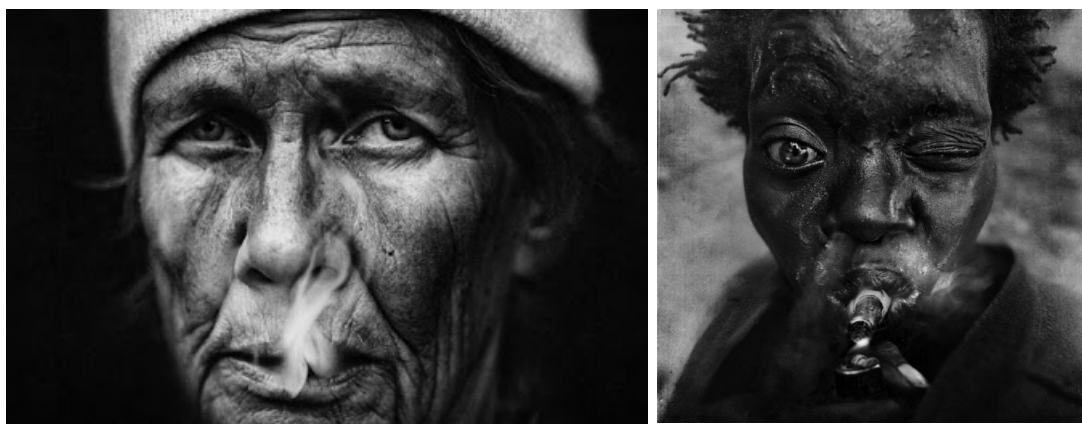

Fig. 3.Fonte: Lee Jeffries. Los Angeles, outubro de 2008. Fig. 4. Fonte: Lee Jeffries. Miami, fevereiro de 2012. 


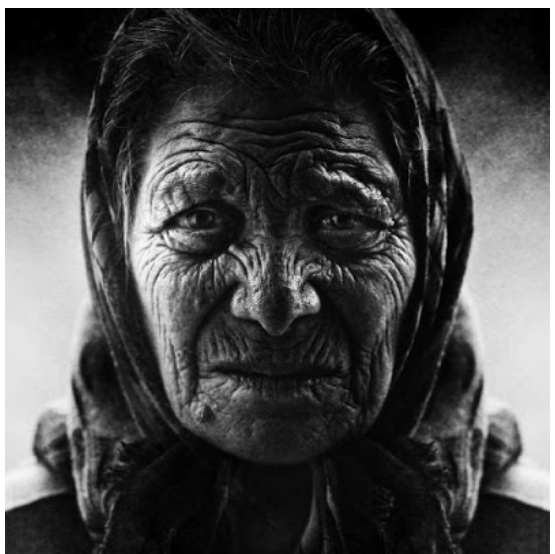

Fig. 5. Fonte: Lee Jeffries. Roma, julho de 2008.

Na figura 3, uma pessoa solta uma fumaça pela boca. Ele/ela também nos apresenta seu rosto enrugado, a testa muito franzida e o olhar frontal fixo. Na figura 4, uma mulher negra ergue a sobrancelha direita com o olho aberto e brilhante, enquanto rebaixa a da esquerda com o olho fechado. Enquanto traga uma espécie de charuto, ela solta fumaça pelas narinas. Na figura 5, uma mulher idosa também fixa o olhar. Ela tem o rosto muito marcado pelas rugas e linhas, a testa contraída e as sobrancelhas rebaixadas ao redor dos olhos. Curiosamente, o lenço como adorno de sua cabeça e preso em laço no pescoço é o que parece informar se tratar de uma senhora. Ao passo que, na figura 3, uma parte do boné ou chapéu de pano faz confundir idade ou gênero. Nestes pontos, mais uma vez, não são os dados ou elementos físicos que são relevantes, mas a proposta de um certo estado de vulnerabilidade experimentada, vivida, em cada um dos retratados.

Neste pequeno conjunto exemplar descrito, podemos notar que os olhares frontais, diretos e próximos propõem ao espectador um efeito relacional, que se coloca como um jogo de imagem: trata-se de compor um olhar, de revelar certa experiência de olhar o outro. Assim, os retratados de Jeffries acabam por evidenciar como se olha para sujeitos oferecidos em certa condição. Mediadora, a imagem fotográfica documental põe em questão uma dimensão estética da realidade social, ou seja, requer que se interrogue sob quais formas de exposição, de aparição, uma realidade social destes sujeitos toma forma.

Segundo Del Rio (2008), a relação do entreolhar posta em uma imagem está na condição imaginária da experiência social que se confunde com a própria representação em uma tentativa de garantia da efetividade da enunciação, aqui, uma situação de fala entre sujeito que olha e sujeito que é olhado. A imagem desativaria o exercício de contextualização ao ser presença, ressaltando uma referencialidade específica, a saber, a própria consciência da prática artística. Deste modo, segundo o autor, torna-se o puro contraplano, postergando a prioridade de intervenção social. Rancière amplia este aspecto 
e discute o tensionamento da imagem no circuito artístico, não se atendo à representação ou ao conteúdo tratado visualmente, mas observando as articulações - se existem e como - entre o representativo e o estético das imagens. Para ele, imagem e realidade não são dimensões que se excluem, mas se articulam, tensionam uma a outra, complexificando as relações entre sentido e circulação social. Não se pode esperar ou crer que uma imagem possa gerar qualquer tipo de intervenção social, mesmo a indignação ativa do espectador, uma vez que a politicidade de uma imagem não reside em seu conteúdo, mas na provocação de rupturas entre os regimes (representativo e estético).

O problema não é opor a realidade às suas aparências. É, sim, construir outras realidades, outras formas de senso comum, ou seja, outros dispositivos espáciotemporais, outras comunidades das palavras e das coisas, das formas e das significações. Esta criação é o trabalho que não consiste em contar histórias, mas sim em estabelecer relações novas entre as palavras e as formas visíveis, a palavra e a escrita, um aqui e um algures, um então e um agora (RANCIÈRE, 2010, p.150).

Há que notar também que nenhuma das Figuras 1, 2, 3, 4 e 5 apresenta outros elementos de cena. Em todas elas, são os closes que impõem uma proximidade e destacam os detalhes de cada retratado. $\mathrm{O}$ formato das faces, a posição da cabeça, a característica da pele, o desalinhamento dos dentes, a direção dos olhos, a abertura da boca, tudo isso compõe indicativos que não são simples elementos factuais - físicos ou biológicos -, mas procuram descrever, ou melhor, enunciar os rostos em seu aspecto humano, atribuir-lhe uma qualidade de humanidade, portanto, este conjunto de elementos físicos é entendido como estado expressivo atuante em cada um dos personagens fotografados.

Nas fotografias de Jeffries, a emersão da figura se faz na relação que se define pelo devir da imagem. Entre o enunciável e o configurado, a face de cada sujeito retratado tece uma imagem que busca uma imersão biográfica, que impõe uma sensação de semelhança. Através de uma cara humana, a realidade é vista dentro do exprimível da condição da espera. A face nunca é uma subjetividade completa, mas interpõe uma expressividade que induz a imagem a uma relação de testemunho imediatamente associado à experiência do olhar. Portanto, diante da interpretação da imagem, é o rosto retratado que estrutura uma espécie de interlúdio da presença e da negociação do olhar/ato de ver.

Em uma leitura específica (JAAR; STRAUSS, 2014), a irregularidade dessa marca é próxima à condição da vida - o rosto de um sujeito se torna denso por uma imbricação entre a regularidade da imagem e a certeza de sua errância no engajamento sensorial, que se faz presença. As faces retratadas, nesse sentido, tornam-se uma maneira contemplativa de vincular a resistência do olhar ao sentido eufórico (FONTANILLE, 2011) da caracterização. Nesses termos, ainda que diante de uma perversa inversão, a experiência do olhar se revela na plasticidade propiciada e na presença significativa da figura humana. Os registros em close das pessoas em situação de rua, no trabalho de Jeffries, consideram 
a ideia do gesto político de ver a imagem (e entregar uma observação) na espera da contaminação da presença, para que ela esteja próxima, para que ela redefina, no plano da expressão, a relação das fotos, o engajamento sensorial e a possibilidade de restituição (aderência do contato das faces marcadas pela anonimidade).

As faces de mulheres, idosos e crianças vulneráveis estabelecem o vínculo com a individuação submergida e apagada na condição social; figuram, os empobrecidos, independentemente de suas diferenças, nomes, histórias e vidas. Elas dinamizam a experiência do ver ao tornar visível a possibilidade de interpretação dos seres, desequilibrados no discurso da relativização do fetichismo da imagem, mas também demarca a experiência da corporeidade em um contexto de estetização: parecemos preocupados com o sofrimento e desamparo destes semblantes, mas o que podemos sentir, no entanto, é certa sensação de prazer, de fruição.

Assim, a fetichização dos semblantes em modo consumo narrativiza uma circulação que proporciona, por um lado, a comunicabilidade perdida e, por outro, o sofrimento interior de cada retratado, explorado com um estatuto artístico. O efeito close, a emergência de uma face do fundo escuro, a duração sensorial do olhar e a intensidade do desejo de olhar não reduzem a objetualidade subjetivante. O sujeito se torna ensaio, personagem, relaxamento entre a alteridade desejada e o exercício de simbolização: o retrato fotográfico na esfera da identificação do olhar.

Cada rosto humano seria exposto em uma tentativa de interrogar a relação existente entre o aspecto visual externo e o estado impalpável - imaterial - interior. Esta dinâmica psicossocial do rosto elaborado nos retratos aqui em jogo não constitui propriamente uma novidade no campo das imagens e das artes. Segundo Courtine e Haroche (2016), uma história do retrato cruzou, inúmeras vezes, com uma história do rosto, mas apenas em paralelo, pois é preciso observar que a emergência da expressão do rosto como signo de leitura atenta para uma demanda cultural que se inicia no século 16.

\section{[...] uma história do rosto é, com efeito, e ao mesmo tempo, a história do controle da expressão, das exigências religiosas, das normas sociais, políticas e éticas que contribuíram desde o Renascimento para o aparecimento de um tipo de comportamento social, sentimental, psicológico fundado no afastamento dos excessos, no silenciar do corpo (COURTINE; HAROCHE, 2016, p.17-18).}

Compreender o rosto como expressão de si e, ao mesmo tempo, elo entre os homens, nas diversas formas de conversações postas nas circunstâncias da vida social, faz parte tanto de um projeto de homem público quanto de civilidade (COURTINE; HAROCHE, 2016, p.18). Expor, exibir, apresentar as várias faces dos sujeitos constituíam tentativas de alinhar o individualismo de costumes à codificação das expressões. Argumentamos que as imagens da série de Jeffries também procuram fazer coincidir o civilizado e o exprimível naquilo que é lícito e aceitável propor ao olhar público. Neste aspecto específico, ainda em 
acordo com Rancière (2005; 2010), o sentido da fotografia documental elaborada por Jeffries não consegue desarticular sua circulação social. A construção desta cena conversacional, nas fotografias de Jeffries, revelariam um paradoxo: a invisibilidade do mundo é das pessoas à margem, em situações de rua, que se mescla com a experiência (fetiche) de serem exibidas na convocação ambígua do olhar. Tal como diz Pinney (2001, p.158), "o abraço sensorial de imagens, o engajamento corporal que a maioria das pessoas tem com obras de arte", privilegia uma estética corporal incorporada (corpothetics), em enfrentamento à representação experiencial desinteressada (EDWARDS, 2016), que textualiza a imagem.

Nas fotos de Jeffries sobre os indivíduos em situação de rua, a rugosidade da pele, a sujeira do rosto, a fixação do olhar, a persona visual e as marcas nos pômulos, junto à emergência do fundo escuro, propagam uma composição cênica do sujeito para o retrato. Todos estes aspectos, em conjunto, ocularizam a percepção da vulnerabilidade oferecida e exposta - as figuras se tornam manifestações de presença (no ensejo de afastar o sentido construído). Em termos da visualidade dos sujeitos vulneráveis, a estetização onipresente reduz o engajamento da foto no sentido de uma duração da interlocução específica: objetos do olhar, efeito-fetiche, expressividade cênica. Essa artefatização, dentro do tempo que a imagem pede, evoca menos o conceito antropológico de experiência, e faz da contemplação da imagem uma unidade de interpretação postural (fruídica e composicional). A imagem pede contexto, mas a presença é sentida no efeito durável, que desequilibra para a sensorialidade.

Em Jeffries, as imagens dos sujeitos vulneráveis, em situação de rua, expostos em sua dupla condição de precariedade e invisibilidade, convocam tais sujeitos a olhar, mas também parecem conformar os seus semblantes. Controlados e expostos ao olhar público, os sujeitos parecem exibir suas expressões desconfiadas, solitárias, cansadas, desamparadas, porém, reguladas e bem delimitadas pela iluminação cuidadosa, pelo enquadramento sistematizado e pelo primeiro plano elaborado que a fotografia lhe proporciona. Assim, os retratados comparecem como em uma galeria de faces humanas, tipificadas e imóveis, alimentando os modelos codificados de olhares sobre outros humanos, fartamente ilustrados pela fotografia documental desde o período moderno, como advertido por Ledo (1998).

Em acordo com as considerações acerca do regime estético das imagens em Rancière (2005), compreendemos que um processo visual de desfazimento dos modelos discursivos acerca dos sujeitos só é possível quando as imagens conseguem elaborar modos de interlocuções efetivas, quando conseguem promover brechas e rupturas nas expectativas que condicionam lugares e posições, desarticulando os pertencimentos. O perigo da estetização é acumular a anonimidade reforçando a perspectiva da modulação sucessiva dos imaginários sobre as figurativizações. Em termos de condição plástica da imagem, a domesticação das faces já não ameaçaria: a irregularidade da vida se regulariza no retrato. Esse jogo é o limite da alteridade apreensível, que substitui a possibilidade de ação civil 
(AZOULAY, 2008) na perda do efeito de singularização. As fotos diminuem a potência do espaço político porque estão mobilizando, preferencialmente, uma contemplação regularizada e tipificada. Tornam-se dificultadoras da própria identificação: seu jogo é a surpresa parcial da sensorialidade, da frontalidade rompante, da máscara do engajamento.

Nos termos da discussão proposta, observamos que tais imagens estão longe de conseguir eliminar a sensação de materialidade sígnica e a ambivalência entre a reprodução do mundo, de uma realidade social, e a estetização da experiência da vulnerabilidade. As fotografias de Jeffries, engajando o espectador a partir de uma familiaridade (acquaintance) com a experiência estética e sensível elaborada pela fotografia documental, podem promover discursos sub-reptícios que acabam associados ao domínio da fetichização dos sujeitos.

Diante dos signos de indignação que seus retratados poderiam mobilizar, o efeitofetiche acaba se alocando na composição de uma cena visual sobre o sujeito retratado, na qual a experiência de ver o outro se torna diluída na expressividade cênica cuidadosamente elaborada da imagem que se quer documental.

\section{Considerações Finais}

Ao repensar a relação do valor de culto e do valor de exposição das imagens em Walter Benjamin, Didi-Huberman (2012), observa que as obras visuais, em geral, não atenderam à unilateralidade da exposição em detrimento do culto, mas em termos dialéticos, hoje, exposição e culto se complementam de modo mais complexo. A perspectiva crítica benjaminiana acerca do valor da imagem repousava em uma condição social totalitária, em que a crise da democracia era concebida como a crise das condições de exposição do sujeito comum.

Reivindicação legítima, segundo Didi-Huberman, mas que, conforme certos usos puderam constatar, ao longo do tempo, acabaram fazendo do pior o melhor, e os sujeitos comuns, de fato, foram expostos, mas não se tornaram outra coisa senão bonecos de títeres, conforme o autor. Seja como for, a exposição de sujeitos comuns, sobretudo os precarizados e vulneráveis, tornou-se uma questão fundamental da vida pública e política trazida à estética (DIDI-HUBERMAN, 2012, p.31). As parcelas de humanos que são expostas hoje, em geral, comparecem ameaçadas por uma lógica que as submetem ao risco constante do desaparecimento.

As fotografias de sujeitos em situação de rua, marcados pela dupla condição - de precariedade e invisibilidade social -, e arroupados pela imagem estetizante em Lost Angels, convertem os retratados em uma imagem pública, ao mesmo tempo sensível e regularizada. As fotografias documentais de Jeffries, dispondo o espectador dentro de uma familiaridade estética e comunicável, não consegue desvincular a plasticidade das presenças dos retratados do domínio de sua fetichização artística e discursiva: a mobilização política funde-se no efeito-fetiche, repertoriando uma composição de cena 
aos sujeitos vulneráveis retratados. No contexto das fotografias do ensaio Lost Angels, a profusão de imagens das várias faces em close das pessoas em situação de rua, marcados pela experiência social, estigmatizante e estigmatizada, se destaca pela forma com que as presenças, sobretudo as faces, são assignadas em um discurso cênico que engendra a foto para o desejo de exibir um certo modo de olhar o outro. Em uma observação mais detida revela que as imagens podem ser artefatos culturais que primam pelo cruzamento entre o artístico e o documental. Nas fotografias de Jeffries, um street photographer para o campo jornalístico, a intensificação da pose, a busca pelo detalhismo visual em close e as miríades de aspectos que atam a imagem à emergência das presenças dos sujeitos retratados compõem uma valorização fruídica da experiência do olhar.

Também, nesta série fotográfica, vincula-se uma potência perspectiva das diferentes maneiras de se perceber o vínculo da imagem com a invisibilidade social dos retratados. O problema da estetização, nesse processo, é acabar referendando uma anonimidade que a visibilização não interrompe no urdimento da foto. Vale ressaltar que o trabalho de analisar imagens não reivindica uma postura política de antemão às fotografias documentais interrogando quais adequações seriam necessárias para configurar uma politicidade à imagem, como argumenta Rancière (2010). Antes, a tarefa de observação procura identificar e ressaltar como as imagens aqui em jogo elaboram um rosto, conferem uma identidade ao sujeito que é contingenciado pela regularização do retrato, em uma cena cuidadosamente depurada.

Nas imagens dos sujeitos em situação de rua feitas pelo fotógrafo, convoca-se o olhar, mas não se consegue contrapor o efeito do enquadramento bem delimitado, operacional, instruído. Nas dobras dessa condição fica a imagem, refém de seu espaço restrito de designação enquanto reverso do olhar humano - sob a rubrica da codificação desejada. Em Lost Angels, a gramática expositiva, a virtualidade da cena e a sensibilidade consolidada interrompem, na imagem, sua operação de vista, seu enriquecimento à espera de um contraplano melhor, futuro. Um contraplano que não seja o que já está formado, que se encontra no ideal, que se paralisa na autenticação visível; mas que permita à imagem não ser o consenso, mas uma outra experiência sensível, enfim, uma transformação não evidente com a circulação social destes olhares.

Angie Biondi é professora do Programa de Pós-graduação em Comunicação e Linguagens da Universidade Tuiuti do Paraná (UTP). É doutora em Comunicação Social pela UFMG.

angiebiondina@gmail.com 
Rafael Tassi Teixeira é professor do Programa de Pósgraduação em Comunicação e Linguagens da Universidade Tuiuti do Paraná (UTP), e do Programa de Mestrado em Cinema e Artes do Vídeo (UNESPAR). É doutor em Sociologia pela Universidad Complutense de Madrid (UCM).

rafatassiteixeira@hotmail.com

\section{Referências}

AZOULAY, A. The civil contract of photography. New York: Zone Books, 2008.

BAURET, G. A fotografia: história, estilos, tendências, aplicações. Lisboa: Edições 70, 1992.

BICKER, P. Portraits of the Homeless by Lee Jeffries. Time, 26 jan. 2012. Disponível em: http://time. com/3785517/portraits-of-the-homeless-by-lee-jeffries/. Acesso em: 25 nov. 2018.

BUTLER, J. Precarious Life: The Powers of Mourning and Violence. New York: Verso, 2004.

Vida precária. Contemporânea - Revista de Sociologia da UFSCar. n. 1, 2011, p.13-33.

2015 .

Quadros de Guerra. Quando a vida é passível de luto? Rio de Janeiro: Civilização Brasileira,

COURTINE, J.-J.; HAROCHE, C. História do rosto: exprimir e calar as emoções. Petrópolis: Vozes, 2016.

DE DUVE, T. A Arte diante do Mal Radical. Ars. V. 7, n. 13, 2009.

DEL RÍO, V. Fotografía Objeto. La Superación de la Estética del Documento. Salamanca: Ediciones Universidad de Salamanca, 2008.

DIDI-HUBERMAN, G. Olhos livres da história. Revista Ícone, vol.16, n.2, 2018, p.161-172.

. Peuples exposés, peuples figurants. L'oeil de l’histoire 4. Paris: Les Éditions de Minuit, 2012.

EDWARDS, E. Rastreando a Fotografia. In: BARBOSA, A.; CUNHA, E.; HIKIJI, R.; NOVAES, S. (Orgs.). A Experiência da Imagem na Etnografia. São Paulo: Terceiro Nome, 2016.

FERRARESE, E. Les vulnérables et le géomètre. Raison Publique. Rennes: Presses Universitaires de Rennes, 2011a, p.17-37.

. Judith Butler's 'not particularly postmodern insight' of recognition. Philosophy \& Social Criticism, v. 37, n. 7, 2011b, p.759-773.

FONTANILLE, J. Corps et Sens. Paris: PUF, 2011.

HARIMAN, R.; LUCAITES, J. The Public Image. Photography and Civic Spectatorship. Chicago: The University of Chicago Press, 2016.

JAAR, A.; STRAUSS, D. Lament of the Images. In: BATCHEN, G.; GIDLEY, M.; MILLER, K.; PROSSER,

J. (Eds.). Picturing Atrocity. Photography in Crisis. London: Reaktion Books, 2014.

LEDO, M. Documentalismo fotográfico: éxodos e identidad. Madrid: Ediciones Cátedra, 1998.

MARQUES, A. C. S.; CORREIO, A. S. A. Rancière e a política das imagens: rosto, olhar e subjetivação na fotografia de JR. Revista Eco-Pós, vol.17, n. 2, 2014, p.1-18.

MOLLAT, M. L'empreinte de la pauvreté médiévale dans les représentations collectives actuelles.

Revue Quart Monde, n.1, 1998. 
PINNEY, C.; THOMAS, N. (Orgs.). Beyond Aesthetics: Art and the Technologies of Enchantment. Oxford: Berg, 2001.

RAMOS, P. H.; VAN V. Rancière: a política das imagens. Princípios: Revista de Filosofia (UFRN), v. 19, n. 32, 14 jul. 2015, p.95-107.

RANCIÈRE, J. A partilha do sensível. Estética e política. São Paulo: Editora 34, 2005.

O espectador emancipado. Lisboa: Orfeu Negro, 2010.

O destino das imagens. Lisboa: Orfeu Negro, 2011.

ROE, A. Animated Documentary. London: Palgrave Macmillan, 2013.

SAMAIN, E. Antropologia, imagens e arte. Um percurso reflexivo a partir de Georges Didi-Huberman. Cadernos de Arte e Antropologia, vol.3, n.2, 2014, p.47-55.

SCHNEIDER, A.; WRIGHT, C. (Orgs.). Contemporary Art and Anthropology. Oxford: Berg, 2006.

SMITH, I. H. Breve história da fotografia: um guia de bolso dos principais gêneros, obras, temas e técnicas. São Paulo: Gustavo Gili, 2018.

SONTAG, S. Sobre fotografia. São Paulo: Companhia das Letras, 2004.

Artigo recebido em 15/09/2019

e aprovado em 29/03/2020. 